\title{
QUEEN'S
UNIVERSITY
BELFAST
}

\section{Lack of association between paw preference and behaviour problems in the domestic dog, Canis familiaris}

Wells, D. L., Hepper, P. G., Milligan, A. D. S., \& Barnard, S. (2018). Lack of association between paw preference and behaviour problems in the domestic dog, Canis familiaris. Applied Animal Behaviour Science.

https://doi.org/10.1016/j.applanim.2018.10.008

Published in:

Applied Animal Behaviour Science

Document Version:

Peer reviewed version

Queen's University Belfast - Research Portal:

Link to publication record in Queen's University Belfast Research Portal

\section{Publisher rights}

Copyright 2018 Elsevier.

This manuscript is distributed under a Creative Commons Attribution-NonCommercial-NoDerivs License

(https://creativecommons.org/licenses/by-nc-nd/4.0/), which permits distribution and reproduction for non-commercial purposes, provided the author and source are cited.

\section{General rights}

Copyright for the publications made accessible via the Queen's University Belfast Research Portal is retained by the author(s) and / or other copyright owners and it is a condition of accessing these publications that users recognise and abide by the legal requirements associated with these rights.

Take down policy

The Research Portal is Queen's institutional repository that provides access to Queen's research output. Every effort has been made to ensure that content in the Research Portal does not infringe any person's rights, or applicable UK laws. If you discover content in the Research Portal that you believe breaches copyright or violates any law, please contact openaccess@qub.ac.uk. 
Lack of association between paw preference and behaviour problems in the domestic dog, Canis familiaris

\section{DEBORAH L. WELLS ${ }^{*}$ PETER G. HEPPER, ADAM D.S. MILLIGAN, SHANIS}

\section{BARNARD}

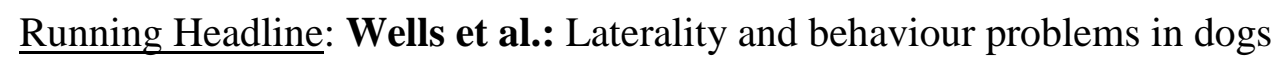

*Author for correspondence

Animal Behaviour Centre

School of Psychology

Queen's University Belfast

Belfast

BT7 1NN

Northern Ireland

UK

Tel: 02890974386

Fax: 02890975486

E-mail: $\underline{\text { d.wells@qub.ac.uk }}$ 


\section{Abstract}

Evidence suggests that paw preferences are related to emotional functioning in the domestic dog. Whether motor bias in this species is related to the display of behaviour problems, which often have their basis in emotional reactivity, is still unknown. This study therefore explored the relationship between lateralised motor behaviour in the form of paw preferences and the occurrence of canine behaviour problems. Fifty-two dogs presenting with one or more behaviour problems, and 61 control animals, had their paw preferences assessed using the commonly employed Kong ${ }^{\mathrm{TM}}$ ball test. The dogs' behavioural profile was determined using the C-BARQ, a psychometric tool designed to provide standardized evaluations of canine behaviour. Analysis revealed a roughly equal split in the proportion of dogs classified as ambilateral and lateralised, although dogs were more like to be ambilateral than left- or rightpawed. Dogs differed significantly in their behavioural profile, with animals in the behaviour problem group displaying more severe patterns of stranger- and dog-directed aggression and fear, non-social fear and touch sensitivity than those in the control group. There was no significant difference in the distribution, direction or strength of the dogs' paw use between the two groups of animals. The dogs' paw preference classification was significantly associated with one of the C-BARQ subscale scores, namely stranger-directed aggression, with left-pawed dogs having lower scores on this subscale than right-pawed or ambilateral animals. The direction of the dogs' paw use in the behaviour problem group was significantly correlated with C-BARQ scores for the subscales of stranger-directed aggression, stranger-directed fear and attention-seeking behaviour, with higher subscale scores associated with increasing rightpawedness. There was no significant correlation between the direction of the dogs' paw use and any of the other C-BARQ subscale scores. The strength of the dogs' paw preferences was not significantly correlated with any of the C-BARQ subscale scores for either the control or 
behaviour problem group of animals. Canine sex was not significantly related to either the dogs' paw preferences or the presentation of behaviour problems. Overall, this study provides little evidence in support of a relationship between paw preference and the occurrence of behaviour problems in the domestic dog. Further, longitudinal, work is recommended in an effort to unravel the ontogeny of lateralisation and its association with emotional reactivity in this species.

Keywords: behaviour problems; C-BARQ; dogs; laterality; paw preferences 


\section{Introduction}

Lateralised motor behaviour has been studied as an observable measure of cerebral functional asymmetry for numerous years (e.g. Harris, 1983; Springer and Deutsch, 1989). The most prominent manifestation of lateralised behaviour in humans is that of handedness (i.e., the predominant use of one hand), with roughly $90 \%$ of people using their right hand for most activities (Annett, 1985; Porac and Coren, 1981).

The preferred use of one hand is associated with greater activity of the contralateral hemisphere (Yousry et al., 1995). The two hemispheres differ significantly in their functions, including emotional processing, although there is still debate as to the exact contribution of each hemisphere in this role (for reviews see Davidson, 1995; Demaree et al., 2005). The right hemisphere is generally considered to be responsible for the processing of fearful information, encouraging withdrawal from novel stimuli and situations (e.g., Ahern and Schwartz, 1979). The left hemisphere, by contrast, largely inhibits fear, encouraging exploration and approach behaviour (e.g., Silbermann and Weingartner, 1986). Dominance, or more frequent use, of one hemisphere over the other predisposes individuals to behave in a certain way. Left-handed or weakly lateralized individuals are more likely to be fearful and prone to maladaptive behaviour than right-handed or strongly lateralized individuals. For example, people with weak hand preferences (i.e., those that are ambilateral) are more likely than those with strong hand preferences to suffer from post-traumatic stress disorder (e.g., Farina et al., 2012), schizophrenia (e.g., Hirnstein and Hugdahl, 2014) and psychosis (Barrantes-Vidal et al., 2013).

Many animals, like humans, display lateralised motor behaviour, most commonly in the form of limb preferences (for reviews see Frasnelli et al., 2012; MacNeilage et al., 2009; Rogers, 
2002; Rogers et al., 2013; Vallortigara et al., 2010; Vallortigara and Rogers, 2005). As in humans, limb preference appears to be related to emotional functioning in some animals (for reviews see Leliveld et al., 2013; Versace and Vallortigara, 2015). Left-handed primates, for example, show greater reactivity, higher stress levels and more fear responses than righthanded individuals (Braccini and Caine 2009; Rogers, 2009, 2010). Gordon and Rogers (2015) found that left-handed marmosets (Callithrix jacchus) were more likely than right-handed animals to exhibit a negative cognitive bias, while non-lateralised chicks (Gallus gallus domesticus) have been shown to exhibit more distress calls in response to the sight of a predator than their more strongly lateralised counterparts (Dharmaretnam and Rogers, 2005).

The following paper explores the relationship between lateralised motor behaviour and the occurrence of behaviour problems in the domestic dog, Canis familiaris. This species demonstrates limb bias in the form of paw preferences at the level of the individual (for review see Siniscalchi et al., 2017). There is already some evidence to suggest that paw preference is related to emotional functioning in the dog. Branson and Rogers (2006), for example, found that dogs with noise sensitivity were more likely to be ambilateral than strongly left- or rightpaw preferent. Dogs with stronger paw preferences (either left or right) have been shown to be more confident than ambilateral animals in both an unfamiliar environment and when presented with novel objects (Marshall-Pescini et al., 2013). More recently, Wells and colleagues (2017) discovered that left paw-preferent dogs harboured a more pessimistic outlook on a cognitive bias test than right-limbed or ambilateral individuals, while Barnard and associates (2017) found an association between ambilaterality and canine personality traits including aggressiveness. The relationship between motor bias and the presentation of behaviour problems is still unknown. Many behaviour problems have their causal basis in anxiety, fear, or other types of emotional reactivity (e.g., see Overall, 1997), and therefore an 
association between the occurrence, nature and/or severity of behaviour problems and limb use might be expected. If this is indeed the case, then it may be possible to predict on the basis of paw use which dogs have the propensity to develop behaviour problems and put appropriate preventative measures into practice. For the purpose of this investigation, dogs presenting with one or more behaviour problems were assessed for their paw preferences using the commonly used Kong ${ }^{\mathrm{TM}}$ ball test. A canine temperament survey was also completed by the dogs' owners to establish specific areas of behavioural concern. A group of dogs without problem behaviours was studied as a control for comparative purposes. It was hoped the investigation would prove informative, not only from an applied perspective, but also from a more fundamental perspective, shedding further light on the merits of motor bias as a tool for assessing vulnerability to stress and poor animal welfare. 


\section{Methods}

\subsection{Subjects}

A total of 113 dogs (64 [56.6\%] males, 49 [43.4\%] females), of mixed breeds, were recruited for the study, $52(46.0 \%)$ presenting with behaviour problems (behaviour problem group) and 61 (54\%) animals without behaviour problems (control group). Dogs in the behaviour problem group (31 males, 21 females, mean age $=5.43$ years $+/$ - SEM 0.43 ) were recruited following consent from their owners via two qualified pet behaviour therapists, one based in Northern Ireland, one based in the Republic of Ireland. Dogs in this group all presented with 1 ( $n=24$, $46.2 \%)$ or $2(n=28,53.8 \%)$ problem behaviours, i.e., behaviours that were considered troublesome to their owners. Control subjects, i.e. dogs without a behaviour problem (33 males, 28 females, mean age $=4.58$ years $+/$ - SEM 0.37) were recruited via response to an email and social media advertising a study on paw preferences addressed to pet owners in Northern Ireland (UK) and the Republic of Ireland. The vast majority of the subjects were castrated $(n=98,86.7 \%)$ and analysis revealed no significant difference in the castration status of male and female animals (Fisher's Exact test $=0.71, \mathrm{df}=1, \mathrm{P}=0.58$ ). Analysis showed no significant difference in the sex (Fisher's Exact test $=0.34, \mathrm{df}=1, \mathrm{P}=0.57$ ), age (Mann-Whitey $\mathrm{U}=1547.00$, $\mathrm{P}=0.82$ ) or castration status (Fisher's Exact test $=1.12 \mathrm{df}=1, \mathrm{P}=0.41$ ) of dogs in the behaviour problem and control groups. None of the dogs had undergone any behavioural training, nor had any disability preventing them from completing the study. None of the subjects with behaviour problems had started their behavioural modification programme at the time of data collection.

\subsection{Apparatus}




\subsubsection{Paw preference testing}

The subjects' paw preferences were tested using a Kong ${ }^{\mathrm{TM}}$ ball (KONG Company, Golden, CO, USA), the most commonly employed method of assessing motor asymmetry in the domestic dog (e.g., Batt et al., 2007; Branson and Rogers, 2006; Marshall-Pescini et al., 2013; Schneider et al., 2013; Wells et al., 2016). A medium-sized Kong ${ }^{\mathrm{TM}}$ ball was used for testing. This is a hollow $10.5 \mathrm{~cm}$ long conical-shaped rubber toy that moves in an erratic manner. The ball has a $2.9 \mathrm{~cm}$ diameter hole at one end, and a smaller $1 \mathrm{~cm}$ diameter hole at the opposite end. Before testing, the toy was filled through the larger hole with moist dog food (Pedigree, original flavour, Waltham Mars, UK) and frozen. Balls were washed thoroughly in between tests.

\subsubsection{Behaviour problem assessment}

To avoid the subjective labelling of behaviour problems via owner report, the dogs' behavioural profiles were assessed using the Canine Behavioral Assessment \& Research Questionnaire (C-BARQ, Hsu and Serpell, 2003). The C-BARQ is a psychometric tool designed to provide standardised evaluations of canine behaviour. The current test comprises 100 questions designed to collect information on how dogs respond to various situations, stimuli and events in their environment. Fourteen behavioural areas are assessed by the tool, namely, stranger-directed aggression, owner-directed aggression, dog-directed aggression, dog-directed fear, familiar dog aggression, trainability, chasing, stranger-directed fear, nonsocial fear, separation-related problems, touch sensitivity, excitability, attachment/attentionseeking and energy. The C-BARQ requires owners to respond to a series of statements pertaining to each of the subscale items (e.g., stranger-directed fear) using a 5-point Likert scale (ranging from 0 [the dog never exhibits this behavioural response] to 4 [the dog always displays this behavioural response]). Three items on the tool are reverse-scored. The C-BARQ 
has proven both reliable and valid and is a powerful instrument in screening dogs for behaviour problems (Hsu and Sun, 2010).

\subsection{Procedure}

Each dog was tested individually in its own home environment, having been food deprived for at least 4 hours. At the start of paw preference testing, the dog was shown, and allowed to sniff, the food-loaded Kong ${ }^{\mathrm{TM}}$ ball. The toy was then placed directly in front of the animal. The paw used to stabilise the Kong ${ }^{\mathrm{TM}}$ by the dog was recorded by the experimenter. A paw use was classified as the animal having one or both paws on the Kong ${ }^{\mathrm{TM}}$ ball, regardless of duration. A separate paw use was considered to have been made when the animal removed its paw from the Kong ${ }^{\mathrm{TM}}$ and replaced one or both of its paws on the object. On occasion, dogs used both paws to stabilise the ball; these occurrences were recorded separately and not included in the analysis; testing was not considered complete until one hundred paw uses (left plus right combined) had been made by the animal, regardless of the number of times dogs employed both paws. For all dogs, the ball was placed centrally in front of the animal once, and 100 paw uses recorded thereafter. While dogs were being tested for their paw preference, owners were asked to complete the C-BARQ, either online or on paper.

\subsection{Data Analysis}

\subsubsection{Paw-preferences}

Binomial $z$-scores were calculated to determine whether the frequency of right- or left-paw use exceeded that expected by chance. An alpha value of 0.05 was adopted for all analyses. A $z$ score greater than +1.96 (two-tailed) reflected a significant left paw preference, whilst a $z$-score less than -1.96 indicated a significant right paw preference. Dogs with $z$-scores between +1.96 and -1.96 were classified as ambilateral. 
A one-way chi-squared analysis was carried out to investigate whether there was a significant difference in the distribution of the dogs' paw preferences. Binomial tests were also conducted to determine whether there was a difference in the number of animals that were: (1) pawpreferent (either to the left or right) $v s$. ambilateral, and; (2) right- $v s$. left-paw preferent.

A directional handedness index (HI) was calculated to quantify each dog's paw preference on a continuum from strongly left-paw preferent (+1) to strongly right paw-preferent (-1). The HI was calculated by dividing the difference between the total number of left and right paw reaches by their sum $(\mathrm{L}-\mathrm{R}) /(\mathrm{L}+\mathrm{R})$ [see Wells 2003]. The strength of the dogs' paw preferences was calculated by taking the absolute value of each HI score (ABS-HI). Mann-Whitney U tests were carried out to explore the effect of group (behaviour problem, control) and sex (male, female see McGreevy et al., 2010; Quaranta et al., 2004; Wells, 2003) on the subjects' HI and ABS-HI scores.

\subsubsection{C-BARQ}

The C-BARQ data were analysed according to the authors' guidelines, giving rise to 14 scores, one for each of the behavioural subscales (e.g., stranger-directed aggression). Mann-Whitney U and Kruskal Wallis tests were conducted to explore the effect of group (behaviour problem, control), paw preference classification (1. ambilateral, left, right, and; 2. ambilateral $v s$. lateralised) and canine sex (male, female) on each of the subscale scores. Bonferroni corrections were applied to control for multiple comparisons.

Chi-squared tests were carried out to determine whether the dogs' paw preference classification (1. ambilateral, left, right, and; 2. ambilateral vs. lateralised), for the behaviour problem group 
only, was associated with the number of behaviours considered problematic by the owners (1, 2).

A series of Pearson product moment correlations were carried out for dogs in the behaviour problem and control groups to explore the relationship between the dogs' $\mathrm{HI}$ and ABS-HI scores and each of the C-BARQ subscale scores.

\section{Ethical Note}

All methods adhered to the Association for the Study of Animal Behaviour/ Animal Behavior Society Guidelines for the Use of Animals in Research (Association for the Study of Animal Behaviour, 2006). Ethical approval for the study was granted by the Research Ethics Committee, School of Psychology, QUB. 


\section{Results}

\subsection{Distribution of paw preference}

The distribution of the dogs' paw preferences was significantly different from that expected by chance alone $\left(\chi^{2}=9.57, \mathrm{df}=2, \mathrm{P}=0.008\right)$. Ambilateral animals $(\mathrm{n}=53,46.9 \%)$ significantly outnumbered the left- $(\mathrm{n}=28,24.8 \%, \mathrm{P}=0.008$, binomial test $)$, and right- $(\mathrm{n}=32,28.3 \%, \mathrm{P}=0.03$, binomial test) pawed subjects. Dogs were no more likely to be paw-preferent $(n=60,54.3 \%)$ than ambilateral $(\mathrm{n}=53,45.7 \%)[\mathrm{P}=0.57$, binomial test $]$.

Analysis revealed no significant difference in the number of ambilateral $v s$. lateralised dogs in the behaviour problem and control groups (Fisher's Exact test $=0.37, \mathrm{df}=1, \mathrm{P}=0.57$ ). There was, likewise, no significant difference (Fisher's Exact test $=0.35, \mathrm{df}=1, \mathrm{P}=0.61$ ) in the number of left/right-pawed dogs between the two groups.

\subsection{Direction of paw preference}

The dogs' HI scores did not differ significantly $(\mathrm{U}=1673.00, \mathrm{P}=0.62)$ between the behaviour problem and control groups. Canine sex was not significantly related to the direction of the dogs' paw use $(\mathrm{U}=1588.00, \mathrm{P}=0.91)$.

\subsection{Strength of paw preference}

The strength of the dogs' paw preferences (ABS-HI scores) did not differ significantly $(\mathrm{U}=1465.50, \mathrm{P}=0.49)$ between the behaviour problem or control group of animals. Male and female dogs did not differ significantly in the strength of their paw use $(\mathrm{U}=1472.00, \mathrm{P}=0.58)$. 


\subsection{Distribution of paw preference and C-BARQ scores}

Dogs in the behaviour problem and control groups differed significantly on $8(57.1 \%)$ of the 14 C-BARQ subscale scores, specifically stranger-directed aggression, stranger-directed fear, dog-directed aggression, familiar dog aggression, dog-directed fear, non-social fear, touch sensitivity and trainability (see Table 1). Dogs in the behaviour problem group presented with higher scores on 7 of these subscales than animals in the control group, with the exception of familiar dog aggression, which was higher in the dogs without behaviour problems. Dogs in the behaviour problem group had lower scores than the control animals on the C-BARQ trainability subscale.

(Table 1 about here)

The dogs' paw preference classification (left, right, ambilateral) was significantly associated with one of the C-BARQ subscale scores, namely stranger-directed aggression (Kruskal-Wallis test=7.47, $\mathrm{P}=0.02$ ). Left-pawed dogs had significantly lower scores (mean score $=0.53+/-0.10$ ) on this subscale than right-pawed (mean score $=0.97+/-0.14 ; \mathrm{U}=593.50, \mathrm{P}=0.03$ ) or ambilateral (mean score $=0.95,+/-0.10 ; \mathrm{U}=1006.50, \mathrm{P}=0.008$ ) animals.

Male and female dogs did not differ significantly on any of their C-BARQ subscale scores ( $\mathrm{P}>0.05$ for all analyses).

A re-analysis of the data on the basis of the dogs' $z$-scores, this time classifying animals as ambilateral or lateralised (showing a significant left or right paw preference), revealed no significant $(\mathrm{P}>0.05)$ difference between the two groups of animals on any of the C-BARQ subscale scores. 
Chi-squared tests on the behaviour problem group of dogs showed no significant association between the dogs' paw preference classification (left, right ambilateral) and the number of behaviours considered problematic by their owners $\left(\chi^{2}=0.84, \mathrm{df}=2, \mathrm{P}=0.66\right)$. Reclassifying the dogs' paw preferences as ambilateral or lateralised equally revealed no significant association with this factor (Fisher's Exact test $=0.67, \mathrm{df}=1, \mathrm{P}=0.57$ ).

\subsection{Direction of paw preference and C-BARQ scores}

A series of Pearson product-moment correlations were carried out for dogs in the behaviour problem and control groups (data were deliberately analysed separately for the two groups given the differences in the animals' C-BARQ profiles, see 3.4.). Analysis showed a significant negative relationship between the behaviour problem dogs' HI scores and 3 of the C-BARQ subscale scores, specifically stranger-directed aggression $(\mathrm{R}=-0.28, \mathrm{~N}=52, \mathrm{P}=0.04)$, stranger-directed fear $(\mathrm{R}=-0.30, \mathrm{~N}=52, \mathrm{P}=0.03)$ and attention-seeking behaviour $(\mathrm{R}=-0.33$, $\mathrm{N}=52, \mathrm{P}=0.01$ ). In all cases, higher subscale scores were associated with increasing rightpawedness (see Figure 1). There was no significant $(\mathrm{P}>0.05)$ correlation between the behaviour problem dogs' HI scores and any of the other C-BARQ subscale scores. HI scores were not significantly correlated $(\mathrm{P}>0.05)$ with any of the C-BARQ subscale scores for dogs in the control group.

(Figure 1 about here)

\subsection{Strength of paw preference and C-BARQ scores}

The dogs' absolute HI scores were not significantly correlated with any of the C-BARQ subscale scores for either the behaviour problem or control group of animals $(\mathrm{P}>0.05$ for all analyses). 


\section{Discussion}

This study explored the relationship between motor laterality in the form of paw preference and the occurrence of behaviour problems in the domestic dog.

The results from this study revealed a roughly equal distribution of lateralised (54\%) and nonlateralised (46\%) dogs as assessed using the Kong ${ }^{\text {TM }}$ ball test; there was therefore no evidence of a population-level bias in paw use. Existing research on the distribution of paw preferences in dogs is conflicting, with some studies highlighting a higher percentage of lateralised than non-lateralised animals (e.g., 75\% lateralised [Tan, 1987]; 77\% lateralised [Branson and Rogers, 2006]; 79\% lateralised [Siniscalchi et al., 2008], and others showing more of an equal distribution of ambilateral and paw-preferent individuals (46\% lateralised [Marshall-Pescini et al., 2013]; 37\% lateralised [McGreevy et al., 2010]; 52\% lateralised [Tomkins et al., 2010]; 57\% lateralised Wells et al., 2017). The results from the present investigation add to the conflict, but are more in line with the majority of studies in this area pointing to a roughly equal split of lateralised and non-lateralised dogs. It is likely that differences in sample constitution (e.g. sex split, castration status), task complexity and other, uncontrolled for, variables (e.g. experimenter handedness), contribute towards this discrepancy in results in dogs, in much the same way as they do in other species (see Rogers, 2009; Strockens et al., 2013; Versace and Vallortigara, 2015). Interestingly, at the neural level, there seems to be some population-level bias in the dog's brain, e.g., for the processing of lexical and intonational information (Andics et al., 2016). The results from the current study, and those reported above, would suggest that either motor bias tasks are not specific enough to show this difference, or that only perceptual biases are lateralised at the level of the population in this species. 
The study revealed no significant difference in the distribution of paw preference between the dogs presenting with behaviour problems and those without. One might have expected a leaning towards left-limb preference or ambilaterality in the behaviour problem group of animals, given that many behaviour problems have their roots in anxiety or similar 'negative' emotions, e.g., fear, frustration, panic (e.g., Overall, 1997). For example, a fearful personality has been shown to predispose dogs to anxieties including noise sensitivity and separation anxiety (Tiira et al. 2016). Despite this, no significant relationship emerged between the dogs' paw preference classification and their C-BARQ scores for the scales of non-social fear (which includes items on noise sensitivity, see also Brandon and Rogers, 2010; Schneider et al., 2013) or separation-related problems. Analysis did admittedly unearth a significant relationship between paw use and stranger-directed aggression. Contrary to what one might have expected, however, given the link between right hemisphere (left limb) dominance and agonistic behaviour (Zappia and Rogers, 1983; Denenberg, 1984; Lippolis et al., 2002; Koboroff et al., 2008), left-pawed dogs actually presented with lower scores on this subscale than right-pawed or ambilateral animals. Further analysis also revealed a negative relationship between the dogs' directional pawedness (HI) scores and some of the C-BARQ subscales (stranger-directed aggression, stranger-directed fear, attention-seeking), with higher scores being more closely correlated with increasing right pawedness. The direction of this result is, again, contrary to what one might have anticipated. One explanation for this might be the paw preference test (Kong ${ }^{\mathrm{TM}}$ ball) employed in this study. Wells and others (2016) have questioned whether the limb used by dogs to support the Kong ${ }^{\mathrm{TM}}$ ball may actually be the non-dominant one, with the dominant limb used for postural support; if this is indeed the case, then the animals classified as right-pawed in the present investigation, may actually have been relying more heavily on their right (as opposed to their left) hemisphere for processing, which would be more in keeping with the emotional valence model of lateralisation (Davidson, 1995). Further study is needed 
to explore this further, ideally using a wider variety of paw preference indices (see Wells et al., 2018).

There was no evidence of any sex effects in this study, either in relation to the animals' paw preferences or their behavioural profiles. Some investigations have found a significant leaning towards right limb use in female dogs and left limb use in males (McGreevy et al., 2010; Quaranta et al., 2004; Wells, 2003). More recent work involving neutered, or a combination of castrated and entire, subjects, however, has typically found no sex differences in dogs' paw use (Barnard et al., 2017; Batt et al., 2008; Branson and Rogers, 2006; Schneider et al., 2012; Wells et al., 2017). This is more in keeping with the results presented here, using a population of mostly (86\%) neutered animals. It seems likely that a hormonal factor is at play in explaining these disparate results (see Geschwind and Galaburda, 1985a, 1985b; Witelson, 1991). However, other, uncontrolled for, individual differences cannot be overlooked. For instance, laterality has been found to be related to personality in some species (e.g., fish- Brown and Bibost, 2014; cats- McDowell et al., 2016), including dogs (Barnard et al., 2017).

The behavioural profile of the dogs in this study did not differ significantly between male and female animals. Some authors have reported sex effects for specific behaviour problems in dogs, e.g., jumping up on people (Rezac et al., 2017), aggression (e.g., Hasiri et al., 2013), phobias (e.g., Bamberger et al., 2006). However, studies that have employed the C-BARQ to assess dogs' behavioural profiles have, as in this investigation, typically found no significant differences between male and female animals (e.g. van den Berg et al., 2010; van der Borg et al., 2017). Other factors may be more pertinent than canine sex in the display of behaviour problems, e.g., age, breed, castration sex, size (see Martinez et al., 2011), and individual study outcomes may therefore depend heavily upon the population of animals under scrutiny. 


\section{Conclusions}

Overall, this study provides little evidence in support of a relationship between paw preference and behaviour problems in the domestic dog. One must consider the possibility that the tool used to assess the behavioural profile of the dogs (C-BARQ) was not sensitive enough to identify problem behaviours. Schneider and colleagues (2013), for example, found very limited support for an association between paw preference and personality (assessed using the C-BARQ) in the domestic dog and questioned whether the aggregated subscales served to mask subtle effects. This is certainly a possibility, as Barnard et al. (2017) recently found a significant association between paw preference and canine temperament, in this case assessed using a more independent dog personality test. As to whether the C-BARQ masked any subtle effects in the present study is unclear, although seems unlikely given the significantly different behavioural profile of the animals in the two groups (perhaps arising from the deliberate attempt to target animals with therapist-assessed behaviour problems).

It must be acknowledged that not all behaviour problems have their roots in anxiety or negative emotions. Genetics, environmental factors, training history, and an array of other independent variables (e.g. pathophysiology, drug action, see Askew, 2003), can all factor into play in the aetiology, development and expression of canine behaviour problems. Moreover, if (as increasingly appears to be the case in dogs) lateralisation is evident only at the individual level, biases may develop ad hoc within the brain of the individual, so perhaps one would not expect a population level correlation between motor bias and behaviour problems. This may also explain the counterintuitive findings observed in the present research. Future studies may benefit from longitudinal work, ideally on larger populations of animals, exploring the development of behaviour alongside that of motor bias in an attempt to unravel the ontogeny of lateralisation and its link to emotional reactivity in the domestic dog. 


\section{Acknowledgements}

The authors would like to thank all of those individuals who allowed their dogs to take part in this study. Special thanks go to Sandra Gilliland and Maureen Byrne for their help with the recruitment of dogs. The financial support of the BBSRC (BB.J021385/1) is gratefully acknowledged. 


\section{References}

Ahern, G. L., Schwartz, G.E. 1979. Differential lateralisation for positive versus negative emotion. Neuropsychologia 17, 693-698.

Andics, A., Gabor, A., Gacsi, M., Farago, T., Szabo, D., Miklosi, A., 2016. Neural mechanisms for lexical processing in dogs. Science 10.1126.

Annett, M., 1985. Left, Right, Hand and Brain: The Right Shift Theory. Lawrence Erlbaum, New York.

Askew, H.R., 2003. Treatment of Behavior Problems in Dogs and Cats. Blackwell Science, Oxford.

Association for the Study of Animal Behaviour., 2006. Guidelines for the treatment of animals in behavioural research and teaching. Anim. Behav. 71, 245-253.

Bamberger, M., Houpt, K.A., 2006. Signalment factors, comorbidity and trends in behavior diagnoses in dogs: 1,644 cases (1991-2001). JAVMA 229, 1591-1601.

Barrantes-Vidal, N., Gross, G.M., Mitjavila, M., Ballespi, S., Kwapil, T.R., 2013. Positive and negative schizotypy are associated with prodromal and schizophrenia-spectrum symptoms. Schizophrenia Res. 145, 50-55.

Barnard S., Wells, D.L., Hepper P.G., Milligan A.D.S., 2017. Association between lateral bias and personality traits in the domestic dog. J. Comp. Psychol. 131, 246-256.

Batt, L.S., Batt, M.S., Baguley, J.A., McGreevy, P.D., 2008. Factors associated with success in guide dog training. J. Vet. Behav. 3, 143-151.

Batt, L.S., Batt, M.S., McGreevy, P.D., 2007. Two tests for motor laterality in dogs. J. Vet. Behav. 2, 47-51.

Braccini, S.N., Caine, N.G., 2009. Hand preference predicts reactions to novel foods and predators in Marmosets (Callithrix geoffroyi). J. Comp. Psychol. 123, 18-25. 
Branson, N.J., Rogers, L.J., 2006. Relationship between paw preference strength and noise phobia in Canis familiaris. J. Comp. Psychol. 120, 176-183.

Brown, C., Bibost, A., 2014. Laterality is linked to personality in the black-lined rainbowfish, Melanotaenia nigrans. Behav. Ecol. Sociobiol. 68, 999-1005.

Davidson, R.J., 1995. Cerebral asymmetry, emotion, and affective style. In: Davidson, R.J., Hugdahl, K. (Eds.), Brain Asymmetry. MIT Press, Cambridge, MA, pp. 361-387.

Demaree, H.A., Everhart, D.E., Youngstrom, E.A., Harrison, D.W., 2005. Brain lateralization of emotional processing: Historical roots and a future incorporating 'dominance'. Behav. Cog. Neurosci. Review. 4, 3-20.

Denenberg, V.H., 1984. Effects of right hemisphere lesions in rats. In: Ardilla A., OstoskySolis P. (Eds.), Right Hemisphere: Neurology and Neuropsychology. Gordon \& Breach, New York, pp. 241-264.

Dharmaretnam, M., Rogers, L.J., 2005. Hemispheric specialization and dual processing in strongly versus weakly lateralized chicks. Behav. Brain Res. 162, 62-70.

Farina, B., Mazzotti, E., Farina, F., 2012. Relationship between handedness and persistent emotional distress in adults experiencing an earthquake. Rivasta Di Psichiatria 47, 309-312. Frasnelli, E., Vallortigara, G., Rogers L.J., 2012. Left-right asymmetries of behaviour and nervous system in invertebrates. Neurosci. Biobehav. Review. 36, 1273-1291.

Geschwind, N., Galaburda, A.M., 1985a. Cerebral lateralization: biological mechanisms, associations, and pathology: II. A hypothesis and a program for research. Neurol. Archive. $42,521-552$.

Geschwind, N., Galaburda, A.M., 1985b. Cerebral lateralization: biological mechanisms, associations, and pathology: III. A hypothesis and a program for research. Neurol. Archive. $42,634-654$. 
Gordon, D.J., Rogers, L.J., 2015. Cognitive bias, hand preference and welfare of common marmosets. Behav. Brain Res. 287, 100-108.

Harris, L.J., 1983. Laterality of function in the infant: Historical and contemporary trends in theory and research. In: G. Young, S. J. Segalowitz, C. M. Corter \& S. E. Trehub (Eds.), Manual Specialization and the Developing Brain. Academic Press, New York, pp. 177-247. Hasiri, A.M., Jahromi, N.O.A., Tabrizi, S.A., 2013. Prevalence of different aggression types and assessment of related determinants in a population of Iranian domestic dogs. Iran. J. Vet. Res. 14, 291-298.

Hirnstein, M., Hugdahl, K., 2014. Excess of non-right-handedness in schizophrenia: metaanalysis of gender effects and potential biases in handedness assessment. Br. J. Psychiat. 205, 260-267.

Hsu, Y.Y., Serpell, J.A., 2003. Developmet and validation of a questionnaire for measuring behavior and temperament traits in pet dogs. JAVMA. 223, 1293-1300.

Hsu, Y., Sun, L., 2010. Factors associated with aggressive responses in pet dogs. Appl. Anim. Behav. Sci. 123, 108-123.

Koboroff, A., Kaplan, G., Rogers, L.J., 2008. Hemispheric specialization in Australian magpies (Gymnorhina tibicen) shown as eye preferences during response to a predator. Brain Res. Bull. 76, 304-306.

Leliveld, L.M.C., Langbein, J., Puppe, B., 2013. The emergence of emotional lateralization: Evidence in non-human vertebrates and implications for farm animals. Appl. Anim. Behav. Sci. $145,1-14$.

Lippolis, G., Bisazza, A., Rogers, L.J., Vallortigara, G., 2002. Lateralisation of predator avoidance responses in three species of toads. Laterality, 7, 163-183.

MacNeilage, P.F., Rogers, L.J., Vallortigara, G., 2009. Origins of the left and right brain. Sci. Amer. 301, 60-67. 
Marshall-Pescini, S., Barnard, S., Branson, N.J., Valsecchi, P., 2013. The effect of preferential paw usage on dogs' (Canis familiaris) performance in a manipulative problem-solving task. Behav. Proc. 100, 40-43.

Martinez, A.G., Pernas, G.S., Casalta, F.J.D., Rey, M.L.S., Palomino, L.F.D., 2011. Risk factors associated with behavioral problems in dogs. J. Vet. Beh. 6, 225-231.

McDowell, L.J., Wells, D.L., Hepper, P.G., Dempster, M., 2016. Lateral bias and temperament in the domestic cat, Felis silvestris. J. Comp. Psychol. 130, 313-320.

McGreevy, P.D., Brueckner, A., Thomson, P. C., Branson, N. J., 2010. Motor laterality in 4 breeds of dogs. J. Vet. Behav. 5, 318-323.

Overall, K.L., 1997. Clinical Behavioral Medicine for Small Animals. Mosby, St Louis. Porac, C., Coren, S., 1981. Lateral Preferences and Human Behavior. Springer-Verlag, New York.

Quaranta, A., Siniscalchi, M., Frate, A., Vallortigara, G., 2004. Paw preference in dogs: relations between lateralised behaviour and immunity. Behav. Brain Res. 153, 521-525.

Rezac, P., Koru, E., Havlicek, Z., Pospisilova, D., 2017. Factors affecting dog jumping on people. Appl. Anim. Behav. Sci. 197, 40-44.

Rogers, L.J., 2002. Lateralization in vertebrates: Its early evolution, general pattern, and development. Adv. Study Behav. 31, 107-161.

Rogers, L.J., 2009. Hand and paw preferences in relation to the lateralized brain. Phil. Trans. Royal Soc. B. 364, 943-954.

Rogers, L.J., 2010. Relevance of brain and behavioural lateralization to animal welfare. Appl. Anim. Behav. Sci. 127, 1-11.

Rogers L.J., Vallortigara., G., Andrew R.J., 2013. Divided Brains: The Biology and Behaviour of Brain Asymmetries. Cambridge University Press, Cambridge. 
Schneider, L.A., Delfabbro, P.H., Burns, N.R., 2013. Temperament and lateralization in the domestic dog (Canis familaris). J. Vet. Behav. 8, 124-134.

Silberman, E.K., Weingartner, H., 1986. Hemispheric lateralization of functions related to emotion. Brain Cog. 5, 322-353.

Siniscalchi, M., d'Ingeo, S., Quaranta, A., 2017. Lateralized functions in the dog brain. Symmetry 9, 71 .

Springer, S.P., Deutsch, G., 1989. Left Brain, Right Brain. W.H. Freeman, New York.

Strockens, F., Gunturkun, O., Ocklenburg, S., 2013. Limb preferences in quadrupedal marsupials and their implications for laterality evolution in mammals. Laterality, 18, 536-575. Tan, U., 1987. Paw preferences in dogs. Int. J. Neurosci. 32, 825-829.

Tiira, K., Sulkama, S., Lohi, H., 2016. Prevalence, comorbidity and behavioral variation in canine anxiety. J. Vet. Behav. 16, 36-44.

Tomkins, L.M., Thomson, P.C., McGreevy, P.D., 2010. First-stepping Test as a measure of motor laterality in dogs (Canis familaris). J. Vet. Behav. 5, 247-255.

Vallortigara, G., Chiandetti, C., Sovrano, V.A. 2010. Brain asymmetry (animal). WIREs Cog. Sci. DOI: 10.1002/WCS.100.

Vallortigara, G., Rogers, L.J. 2005. Survival with an asymmetrical brain: Advantages and disadvantages of cerebral lateralization. Behav. Brain Sci. 28, 575-633.

van den Berg, S.M., Heuven, H.C.M., van den Berg, L., Duffy, D. L., Serpell, J.A., 2010. Evaluation of the C-BARQ as a measure of stranger-directed aggression in three common dog breeds. Appl. Anim. Behav. Sci. 124, 136-141.

Van der Berg, J.A.M., Graat, E.A.M., Beerda, B., 2017. Behavioural testing based breeding policy reduces the prevalence of fear and aggression related behaviour in Rottweilers. Appl. Anim. Behav. Sci. 195, 80-86. 
Versace, E., Vallortigara, G., 2015. Forelimb preferences in human beings and other species: multiple models for testing hypotheses on lateralization. Frontiers Psychol. 6, 233.

Wells, D. L., 2003. Lateralised behaviour in the domestic dog, Canis familiaris. Behav. Process. 61, 27-35.

Wells, D.L., Hepper, P.G., Milligan, A.D.S., Barnard, S., 2016. Comparing lateral bias in dogs and humans using the Kong ${ }^{\mathrm{TM}}$ ball test. Appl. Anim. Behav. Sci. 176, 70-76.

Wells, D.L., Hepper, P.G., Milligan, A.D.S., Barnard, S., 2017. Cognitive bias and paw preference in the domestic dog, Canis familiaris. J. Comp. Psychol. 131, 317-325.

Wells, D.L., Hepper, P.G., Milligan, A.D.S., Barnard, S., 2018. Stability of motor bias in the domestic dog, Canis familiaris. Behav. Process. 149, 1-7.

Witelson, S.F., 1991. Neural sexual mosaicism: Sexual differentiation of the human temporoparietal region for functional asymmetry. Psychoneuroendocrinology 16, 131-153.

Yousry, T.A., Schmid, U.D., Jassoy, A.G., Schmidt, D., Eisner, W.E., Reulen, H.J., et al., 1995. Topography of the cortical motor hand area - prospective-study with functional MR-imaging and direct motor mapping at surgery. Radiology 195, 23-29.

Zappia, J.V., Rogers, L.J., 1983. Light experience during development affects asymmetry of forebrain function in chickens. Dev. Brain Res. 11, 93-106. 


\section{Table Legend}

Table 1. Mean (+/-SEM) C-BARQ subscale scores for dogs in the experimental and control groups. The Mann-Whitney U test results are presented. $P$ values were corrected for multiple comparisons. * indicates a significant effect 


\section{Figure Legend}

Figure 1. Scattergrams showing the relationship between the behaviour problem group's Handedness Index (direction of paw use) scores and mean C-BARQ scores for a) strangerdirected aggression, b) stranger-directed fear and c) attention-seeking 
Table 1

\begin{tabular}{|c|c|c|c|}
\hline \multirow[t]{2}{*}{ C-BARQ subscale item } & \multicolumn{2}{|c|}{ Behaviour problem Control } & \multirow[t]{2}{*}{ Mann-Whitney U } \\
\hline & Mean (SEM) & Mean (SEM) & \\
\hline Stranger-directed aggression & $1.08(0.12)$ & $0.65(0.07)$ & $\mathrm{U}=1111.50, \mathrm{P}=0.006$ * \\
\hline Owner-directed aggression & $0.28(0.08)$ & $0.16(0.04)$ & $\mathrm{U}=1491.50, \mathrm{P}=0.54$ \\
\hline Dog-directed aggression & $1.75(0.20)$ & $1.02(0.11)$ & $\mathrm{U}=1107.00, \mathrm{P}=0.008 *$ \\
\hline Familiar-dog aggression & $0.35(0.09)$ & $0.62(0.09)$ & $\mathrm{U}=1460.50, \mathrm{P}=0.004 *$ \\
\hline Dog-directed fear & $1.74(0.16)$ & $0.65(0.09)$ & $\mathrm{U}=646.00, \mathrm{P}<0.001 *$ \\
\hline Stranger-directed fear & $1.36(0.17)$ & $0.47(0.09)$ & $\mathrm{U}=893.00, \mathrm{P}<0.001 *$ \\
\hline Non-social fear & $1.65(0.13)$ & $0.90(0.08)$ & $\mathrm{U}=865.50, \mathrm{P}<0.001 *$ \\
\hline Touch sensitivity & $1.19(0.14)$ & $0.75(0.09)$ & $\mathrm{U}=1086.50, \mathrm{P}=0.01 *$ \\
\hline Separation-related problems & $0.80(0.10)$ & $0.67(0.09)$ & $\mathrm{U}=1370.00, \mathrm{P}=0.27$ \\
\hline Excitability & $2.64(0.10)$ & $2.44(0.10)$ & $\mathrm{U}=1389.50, \mathrm{P}=0.26$ \\
\hline Attention-seeking & $2.42(0.11)$ & $2.34(0.11)$ & $\mathrm{U}=1457.00, \mathrm{P}=0.46$ \\
\hline Chasing & $2.45(0.15)$ & $2.38(0.13)$ & $\mathrm{U}=1490.00, \mathrm{P}=0.68$ \\
\hline Trainability & $2.55(0.08)$ & $2.77(0.07)$ & $\mathrm{U}=1938.00, \mathrm{P}=0.04 *$ \\
\hline Energy & $2.37(0.14)$ & $2.18(0.13)$ & $\mathrm{U}=1386.00, \mathrm{P}=0.39$ \\
\hline
\end{tabular}


Figure 1.

a)

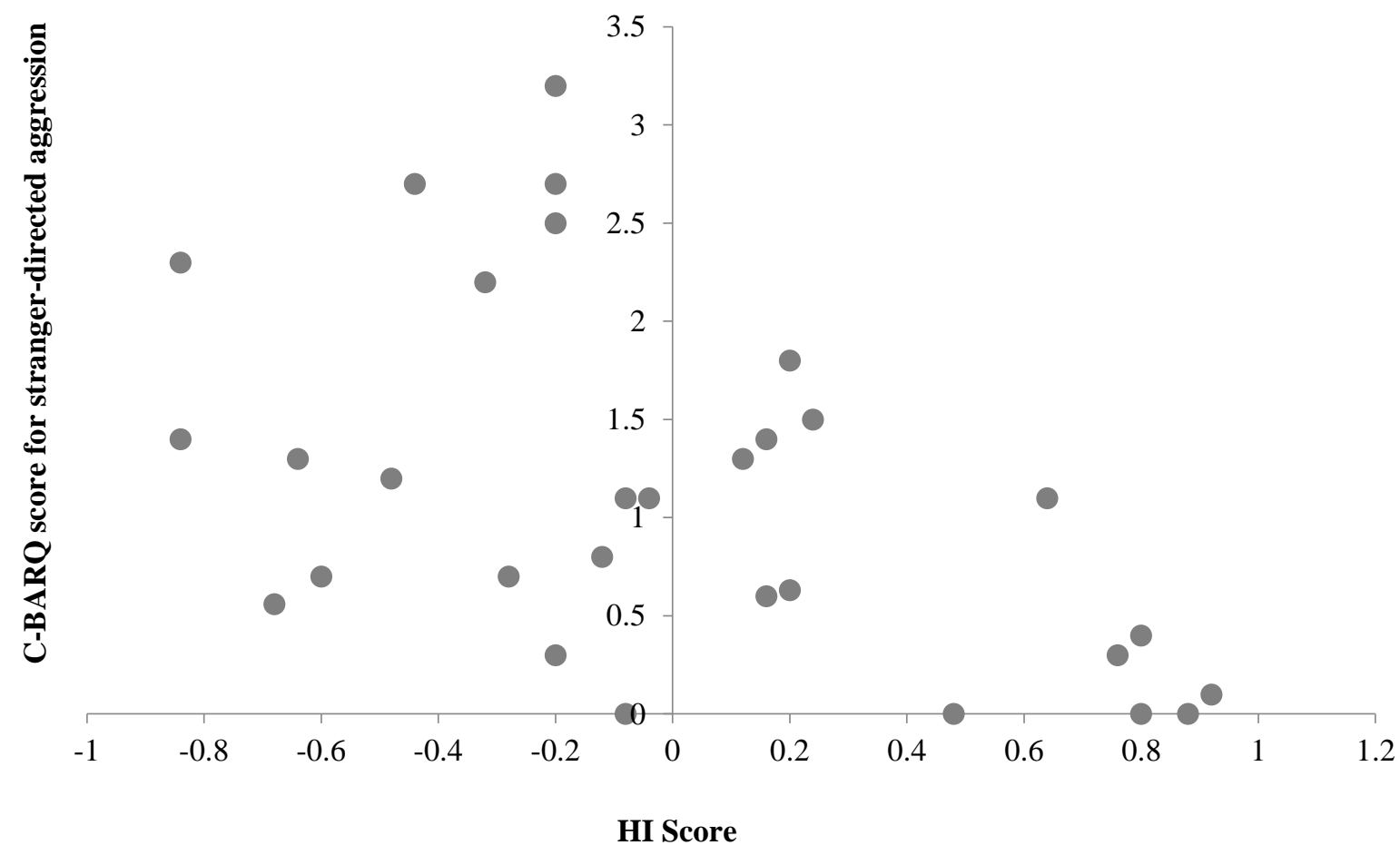


b)

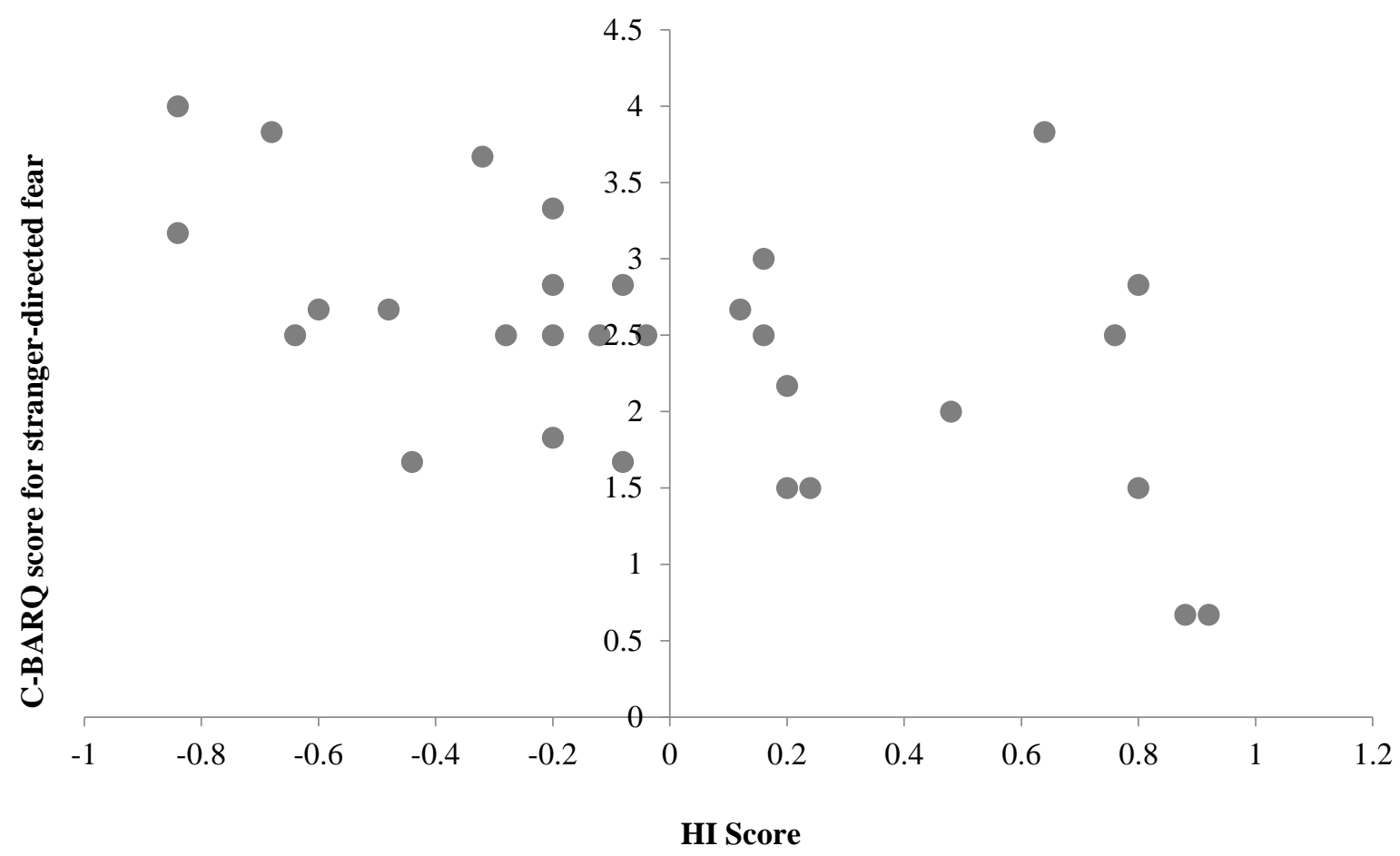

c)

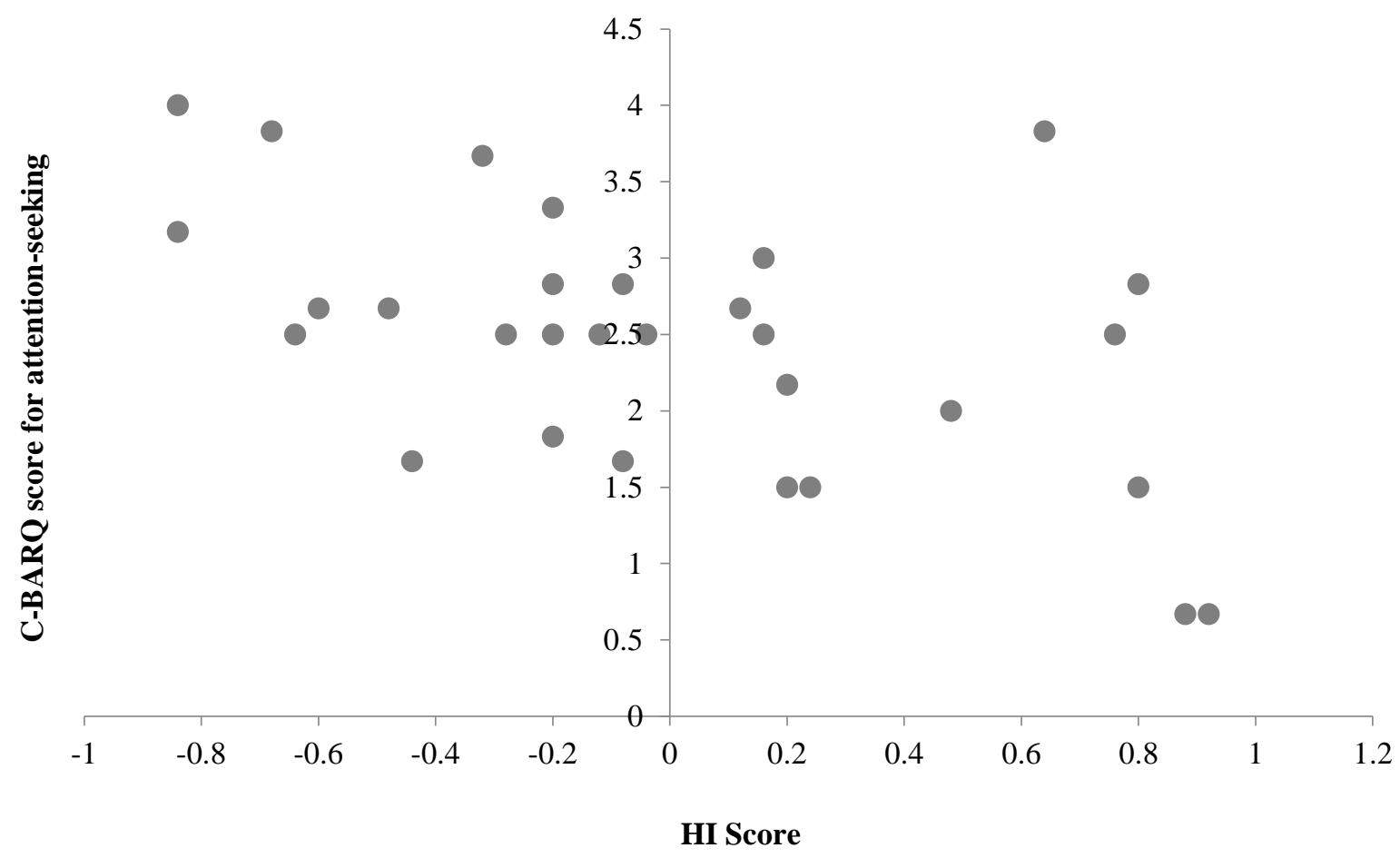

